\title{
A misquoted mutation in exon16 of the BRCA2 gene
}

Received: 6 September 2005/ Accepted: 6 November 2005 / Published online: 25 January 2006

(C) The Japan Society of Human Genetics and Springer-Verlag 2006

\begin{abstract}
A pathogenic mutation in the BRCA2 gene, nt7602del16, has been misquoted as a mutation, possibly due to the incorrect inclusion of the last 16 nucleotides of exon 15 of the BRCA2 gene as part of the intron15exon16 BRCA2 gene sequence in publicly available databases. This was concluded following mutational screening by sequencing and enzymatic mapping of the BRCA2 gene exon15-exon16 region in DNA from peripheral blood samples from a total of 74 breast cancer and non-breast cancer patients as well as healthy individuals and the cell line MCF7. Careful interpretation of genetic variants and direct feedback to the corresponding sequence databases prevent systemic errors by integrating updated data into broadly referenced sources.
\end{abstract}

Keywords BRCA2 gene mutations - Mutation databases - Breast cancer risk-management

\section{Introduction}

Germline mutations in the BRCA1 (GenBank: MIM 113705; http://www.ncbi.nlm.nih.gov) and BRCA2 (GenBank: MIM 600185) genes have been implicated as causal factors in 4-8\% of all breast cancer cases occurring in women, and in more than $70 \%$ of early familial breast cancer (McClain et al. 2005). Since the identification of the BRCA2 gene sequence (Wooster et al. 1995), a large body of research has been dedicated to identifying BRCA2 mutations and their prevalence in patients of different

A. Kataki $(\bowtie) \cdot$ A. Derventzi $\cdot$ I. Gomatos

M.M. Konstadoulakis

Laboratory of Surgical Research,

1st Department of Propaedeutic Surgery,

Hippokrateio Hospital, University of Athens,

Vas. Sofias 114, 11527 Athens, Greece

E-mail: labsures@med.uoa.gr

Tel.: + 30-210-7486534

Fax: + 30-210-7707574 populations as well as understanding the role of this gene in breast cancer, cellular homeostasis and carcinogenesis (McClain et al. 2005; Shivji and Venkitaraman 2004). Evaluation of BRCA2 germline mutations and polymorphisms is a key determinant in prognosis, risk assessment and therapeutic strategies for breast cancer and other BRCA2-related malignancies (for clinician guidelines, see National Cancer Institute, Breast Cancer Prevention; http://www.cancer.gov).

\section{Materials and methods}

The study was performed in accordance with current institutional ethical committee requirements.

\section{Patients}

In the present study, a total of 74 subjects were genetically screened, including 35 patients diagnosed with breast cancer, 24 non-breast cancer patients (19 colon cancer patients, 2 Crohn's disease patients and 3 patients suffering from familial hypertrophic cardiomyopathy) as well as 12 non-affected breast cancer family members and 3 healthy individuals.

Genetic analysis

DNA was isolated from peripheral blood lymphocytes using standard methods or the FlexiGene DNA Kit (Qiagen, Hilden, Germany), according to the manufacturer's instructions. The BRCA2 exon16 was amplified as described previously (Kataki et al. 2005).

Sequence analysis

The BRCA2 gene sequence region extending between exon 16 and part of the preceding intron 15 and 
the concomitant intron 16, as well as BRCA2 exon 15, were sequenced bidirectionally as described previously (Armakolas et al. 2002) in an automated system (Macrogen Sequencing Service). Primers designed to amplify into the the BRCA2 intron 15-exon 16 border covering the $16 \mathrm{bp}$ region (according to the NHGRI BCIC database) were: forward primer: TGTGTAGGTGTTCTCATAAACAG; reverse primer: AAAGAGGGATGAGGAATAC (the $16 \mathrm{bp}$ of interest are italicised).

\section{Enzymatic mapping}

The 325 bp PCR-amplified DNA from biological samples was digested with the restriction enzyme PvuII (New England Biolabs, Beverly, MA), which recognises the sequence CAGCTG.

\section{Immunocytochemistry}

BRCA2 protein integrity was monitored in MCF7 cells by immunofluorescence staining with a polyclonal antibody specific for the carboxy-terminal amino acids 3245-3418 of human BRCA2 protein (BRCA2 Ab-2; Calbiochem, San Diego, CA).

\section{Results}

During the course of a mutational analysis of the entire coding sequence of the BRCA2 gene in DNA isolated and PCR-amplified (Kataki et al. 2005) from peripheral blood lymphocytes from breast and ovarian cancer patients and non-affected breast cancer family members, we encountered some initially striking observations concerning two of these samples, both with a distinct family history of disease. Aligning sequencing data from these samples to the BRCA2 gene exon 16 sequence listed in an established database (NHGRI Breast Cancer Information Core; http://www.research.nhgri.nih.gov), demonstrated a large deleterious deletion (nt7602del16) of 16 nucleotides (GTGTTCTCATAAACAG) in the intron15-exon 16 border of the BRCA2 gene in all individuals. Literature and database searches revealed that the nt7602del16 mutation has been reported previously in a Japanese population genetics study (Katagiri et al. 1998) and is listed in the Human Gene Mutation Database (HGMB: CD982507; http://www.archive.uwcm.ac.uk). This nt7602del16 (aa2534-2539) mutation of BRCA2 exon16 was detected in four members of a breast-cancer-affected family (Katagiri et al. 1998) and was regarded as pathogenic as it results in an early termination codon at aa2545 of the BRCA2 protein.

However, the sequencing data in our study provided proof that these nt7602del16 carriers were actually
Fig. 1a,b Representative sequence analyses of intron 15 exon 16 and exon 15-intron 15 region of the BRCA2 gene. a Sequencing data of the PCRamplified intron 15-exon 16 DNA region from MCF7 cells; lack of superimposing peaks signifies homozygosity. b Sequence data of the BRCA2 exon 15-intron 15 region from a breast cancer patient blood sample containing the 16 nucleotides without indications of heterozygosity. The $16 \mathrm{bp}$ sequence of interest is indicated by a line above the corresponding nucleotides a intron15 - exon16

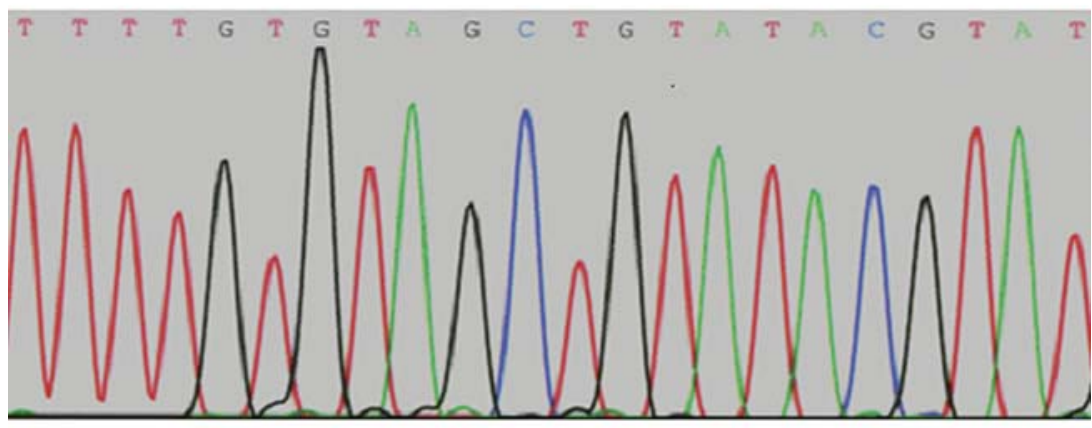

b

exon 15 - intron 15

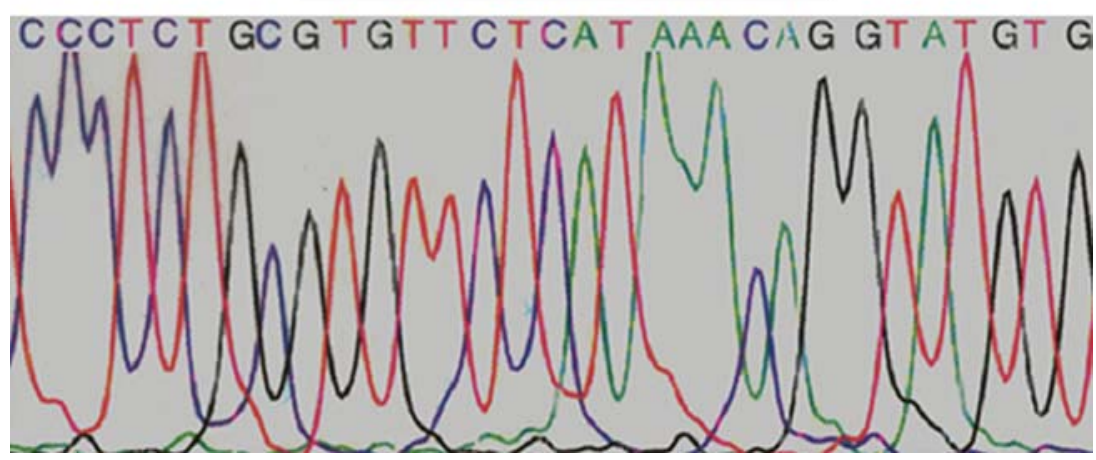


homozygous with regard to this mutation (sequencing data in this region has no superimposing peaks; Fig. 1a). This motivated us into performing more extensive tests on another six randomly selected samples. Since the sequencing data provided evidence of the same homozygous deletion in all DNA samples tested, an even larger number of subjects of broader origin - including a random choice of 35 breast cancer patients and 12 nonaffected breast cancer family members previously screened for entire BRCA2 gene mutations (Armakolas et al. 2002), as well as another 19 colon cancer patients, 2 Crohn's disease patients, 3 familial hypertrophic cardiomyopathy patients and 3 healthy individuals - was investigated by enzymatic mapping of the 325 bp PCRamplified DNA region of interest. The restriction enzyme $P v u \mathrm{II}$ recognizes the sequence CAGCTG, which is expected to be intact in samples containing the 16 nucleotides of interest in BRCA2 exon16. PvuII failed to digest all of the studied samples, indicating that none of them contain this 16 bp region in exon16 (Fig. 2). In parallel, a new pair of PCR primers specific for the described BRCA2 intron 15-exon 16 sequence was designed and used in six representative samples. However, there seem to be no target sequence present in any of the studied samples, since this sequence failed to amplify in all tested DNA.

All the screening tests were also performed on DNA isolated from MCF7 cells, which have repeatedly served as a BRCA2-positive control in a variety of studies (Data Sheet PC146 Rev.13/9/2004, Calbiochem; Vissac et al. 2002). According to these results, MCF7 cells also contain the nt7602 $16 \mathrm{bp}$ deletion, a fact indicative of expression of a BRCA2 protein truncated at aa2545 in these BRCA2-positive cells. Immunocytochemical staining of MCF7 cells with an antibody specific for the carboxy-terminal aa3245-3418 of human BRCA2 protein was performed. As expected, but contrary to all previous indications, MCF7 cells were clearly crossreactive with the BRCA2 antibody, illustrating the unequivocal expression of an integral and functional BRCA2 protein in MCF7 cells.

In summary, our experimental data show that all subjects including breast cancer patients and healthy subjects, were homozygous carriers of the BRCA2 nt7602del16 mutation, while expression of intact BRCA2 protein was demonstrated in samples expected to contain a BRCA2 protein truncated at aa 2545 if the deletion existed. These observations directed our efforts towards investigating the validity of the information listed in the databases. Additional sequence analysis of the exon 15 region of BRCA2 in a selection of the previously screened samples revealed that the $16 \mathrm{bp}$ sequence we suspected as deleted when listed as part of BRCA2 intron 15-exon 16, is actually located in the exon 15-intron 15 border of the BRCA2 gene (Fig. 1b). In particular, the GTGTTCTCATAAACAG sequence represents the terminal nucleotides of BRCA2 exon 15 but have been erroneously allocated to the intron 15exon 16 sequence in certain highly referenced database (Fig. 3). This conclusion from our research data was ultimately affirmed by sequence data provided in $\mathrm{Na}$ tional Center for Biotechnology Information database link (NCBI Evidence Viewer, BRCA2 exon16: NT024524.13; U43746; http://www.ncbi.nih.gov/mapview).

\section{Discussion}

The extensive clarification of our initial observations regarding the presence of the nt7602del16 mutation in exon 16 of the BRCA2 gene in a total of 74 subjects and the MCF7 cell line, verified that the nt7602del16 has been misquoted as a mutation. The listed (HGMB: CD982507) nt7602del16 mutation does not exist. Incorrect placement of this sequence the end of BRCA2 exon 15 in this database apparently accounts for misinterpretation of this sequence alignment as a deletion in addition to a ccc $\rightarrow$ ctc alteration listed as intronic $($ int15 +5$)$ mutation in the same study (Katagiri et al. 1998).

Publicly accessible sequence databases and BRCA1/2 polymorphisms and mutation registries (e.g. Breast Cancer Information Core; Szabo et al. 2000) are indispensable tools both for clinicians and geneticists as reference data (see Wolfsberg et al. 2003). Notably, in the

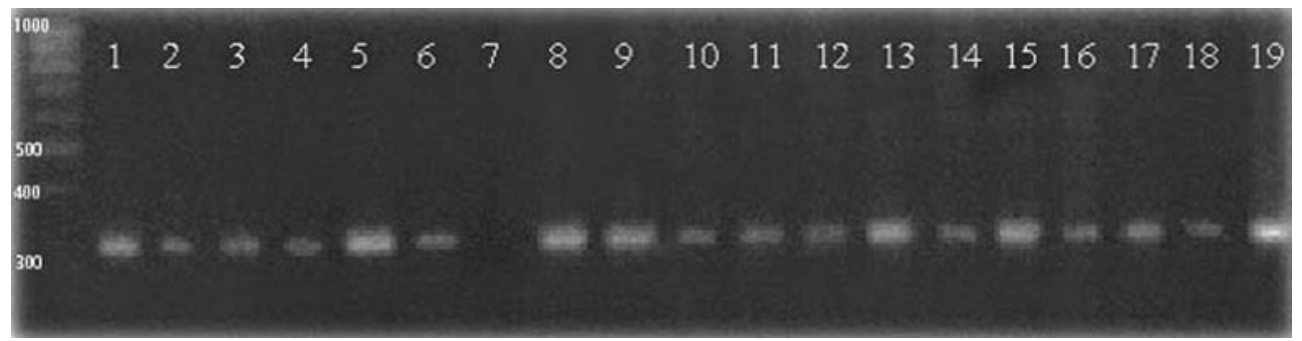

Fig. 2 Example of $P v u$ II-restriction analysis. A random selection of PvuII-digested PCR-amplified 325 bp DNA regions of BRCA2 exon 16 from diverse samples of breast cancer and non-breast cancer patients (lanes $1-6,8-15$ ), healthy individuals (lanes 16-18) and MCF7 cells (lane 19). Lane 7 Negative control. PvuII treatment did not produce the expected digestion products $(244$ and $81 \mathrm{bp}$ ) in any of the samples, indicating absence of the enzyme's recognition site in the DNA region of interest. Sizes (bp) of DNA-size markers are noted 


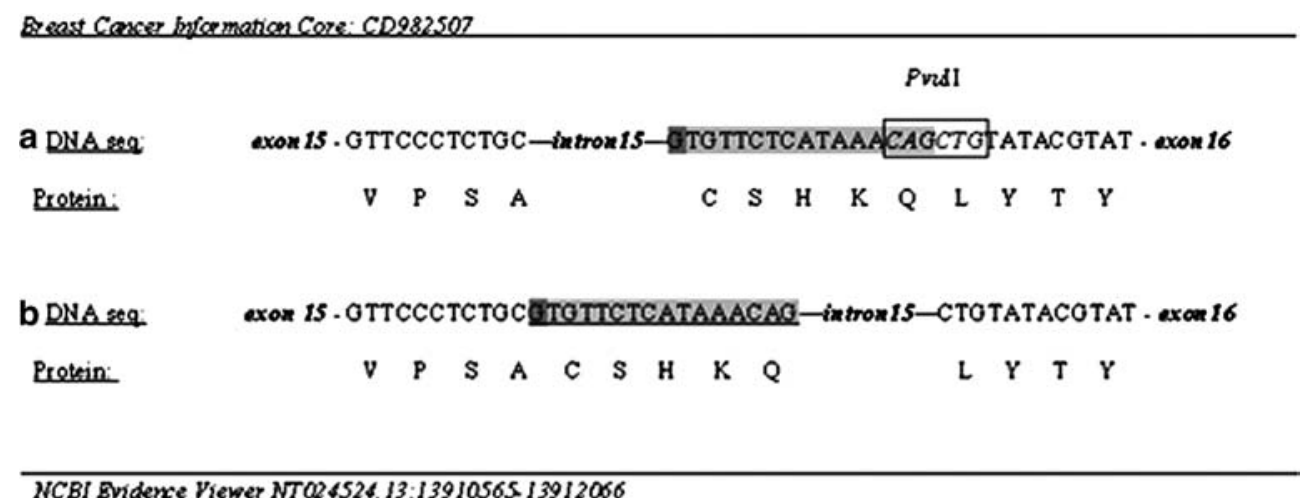

NCBI Endence Viewer NT024524.13:13910565.13912066

Fig. 3 a Incorrect alignment of 16 nucleotides (shaded area) in the borders of BRCA2 intron 15-exon 16 has resulted in a misquoted mutation (CD982507). b Correct BRCA2 exon 15-intron 15exon 16 sequence: the shaded $16 \mathrm{bp}$ are the final nucleotides of

case of BRCA1/2 pathogenic mutation carriers, riskmanagement strategies dictate treatment designs, including drastic therapeutic interventions such as prophylactic mastectomy (Rebbeck et al. 2004). This alone highlights the role of databases in areas that extend beyond researcher confidence, even reaching public health issues. Our experience in screening high-risk populations for BRCA1/2 mutations (Kataki et al. 2005; Armakolas et al. 2002) has taught us diligence and vigilance in interpreting scientific data by means of databases. These reported population-specific polymorphisms, pathogenic mutations and genotype-phenotype correlations acquire reference value for numerous investigators involved in defining the genetic background of breast cancer, and therefore, data accuracy is critical. Optimising the information provided in databases is an ongoing interactive process crucial to genetic epidemiological research.

\section{References}

Armakolas A, Ladopoulou A, Konstantopoulou I, Pararas B, Gomatos IP, Kataki A, Konstadoulakis MM, Stathopoulos GP, Markopoulos C, Leandros E, Gogas I, Yannoukakos D, Androulakis G (2002) BRCA2 gene mutations in Greek patients with familial breast cancer. Hum Mutat 19:81-82

Katagiri T, Kasumi F, Yoshimoto M, Nomizu T, Asaishi K, Abe R, Tsuchiya A, Sugano M, Takai S, Yoneda M, Fukutomi T, Nanba K, Iino Y, Karino T, Ayabe H, Hara S, Kajiwara T, Houga S, Shimizu T, Toda M, Yamazaki T, Uchida T, Kunimoto T, Sono H, Kurebayashi J, Shimotsuma K, Nakamura Y, Miki Y (1998) High proportion of missense mutations of the BRCA1 and BRCA2 genes in Japanese breast cancer families. J Hum Genet 43:42-48
BRCA2 exon 15. The corresponding BRCA2 protein amino acid sequence is shown below each DNA sequence. Boxed nucleotides $P v u I I$ restriction site

Kataki A, Gomatos I, Pararas N, Armakolas A, Panousopoulos D, Karantzikos G, Voros D, Zografos G, Markopoulos C, Leandros E, Konstadoulakis MM (2005) Identification of germiline BRCA1 and BRCA2 genetic alterations in Greek breast cancer moderate-risk and low-risk individuals - correlation with clinicopathological data. Clin Genet 67:322-329

McClain MR, Palomaki GE, Nathanson KL, Haddow JE (2005) Adjusting the estimated proportion of breast cancer cases associated with BRCA1 and BRCA2 mutations: public health implications. Genet Med 7:28-33

Rebbeck TR, Friebel T, Lynch HT, Neuhausen SL, van 't Veer L, Garber JE, Evans GR, Narod SA, Isaacs C, Matloff E, Daly MB, Olopade OI, Weber BL (2004) Bilateral prophylactic mastectomy reduces breast cancer risk in BRCA1 and BRCA2 mutation carriers: the PROSE Study Group. J Clin Oncol 22:1055-1062

Shivji MK, Venkitaraman AR (2004) DNA recombination, chromosomal stability and carcinogenesis: insights into the role of BRCA2. DNA Repair 3:835-843

Szabo C, Masiello A, Ryan JF, Brody LC (2000) The breast cancer information core: database design, structure, and scope. Hum Mutat 16:123-131

Vissac C, Peffault De Latour M, Communal Y, Bignon YJ, Bernard-Gallon DJ (2002) Expression of BRCA1 and BRCA2 in different tumor cell lines with various growth status. Clin Chim Acta 320:101-110

Wolfsberg TG, Wetterstrand KA, Guyer MS, Collins FS, Baxevanis AD (2003) A user's guide to the human genome. Nat Genet $35: 1 \mathrm{~s}$

Wooster R, Bignell G, Lancaster J, Swift S, Seal S, Magnion J, Collins N, Gregory S, Gumbs C, Micklem G, Barfoot R, Hamoudi R, Patel S, Rice C, Biggs P, Hashim Y, Smith A, Connor F, Arason A, Gudmundsson J, Ficenec D, Kalsell D, Ford D, Tonin P, Bishop DT, Spurr NK, Ponder BAJ, Eeles $\mathrm{R}$, Peto J, Devilee $\mathrm{P}$, Cornelisse $\mathrm{C}$, Lynch $\mathrm{H}$, Narod SA, Lenoir G, Egilsson V, Bakadttir RB, Easton DF, Bentley DR, Futreal PA, Ashworth A, Stratton MR (1995) Identification of the breast cancer susceptibility gene BRCA2. Nature 378:789-792 